\title{
Miniaturized cardiopulmonary bypass: the Hammersmith technique
}

\author{
Aziz Momin ${ }^{1,2}$, Mansour Sharabiani ${ }^{1,2}$, John Mulholland ${ }^{1,2}$, Gemma Yarham ${ }^{1,2}$, Barnaby Reeves ${ }^{1,2}$, \\ Jon Anderson ${ }^{1,2}$ and Gianni Angelini $i^{1,2^{*}}$
}

\begin{abstract}
Background: Conventional Cardiopulmonary Bypass (CCPB) is a trigger of systemic inflammatory reactions, hemodilution, coagulopathy, and organ failure. Miniaturised Cardiopulmonary Bypass (mCPB) has the potential to reduce these deleterious effects. Here, we describe our standardised 'Hammersmith' mCPB technique, used in all types of adult cardiac operations including major aortic surgery.

Methods: The use of $\mathrm{mCPB}$ remains limited by the diversity of technologies which range from extremely complex, micro systems to ones very similar to CCPB. Our approach is designed around the principle of balancing the benefits of miniaturisation; reducing foreign surface area while maintaining patient safety.

Results: From January 2010 to March 2011, a single surgeon performed 184 consecutive operations (Euro score Logistic 8.4+/-9.9): 61 aortic valve replacements, 78 CABGs, 25 aortic valve replacement and CABG and 17 other procedures (major aortic surgery, re-do operations or double/triple valve replacements).

Our clinical experience suggests that:

i. Venous drainage is optimally maintained using kinetic energy.

ii. Venous collapse pressure depends on the patient's anatomy and cannula size, but most importantly on the negative pressure generated by venous drainage.

iii. The patient-prime interaction is optimised with antegrade and retrograde autologous priming, which mixes the blood and prime away from the tissues and results in a reduced oncotic destabilization.

iv. $m C P B$ is a safe and reproducible technique
\end{abstract}

Conclusion: The Hammersmith mCPB is a "next generation" system which uses standard commercially available components. It aims to maintain safety margin and the benefit of miniaturised system whilst reducing the human factor demands.

Keywords: Mini CPB, Conventional CPB, Heart surgery, Mini-Cardiopulmonary, Bypass

\section{Background}

Conventional cardiopulmonary bypass $(\mathrm{CCPB})$ remains the most common type of cardiopulmonary bypass (CPB), with only $4-10 \%$ of operations using miniaturised $\mathrm{CPB}(\mathrm{mCPB})$. Potential advantages of $\mathrm{mCPB}$ include a reduction in the deleterious effects of $\mathrm{CPB}$, patient derived volume addition, and better physiological compatibility.

An early, small-randomized controlled trial (RCT) [1] reported that $\mathrm{mCPB}$ "marginally" reduced coagulation

\footnotetext{
* Correspondence: g.d.angelini@imperial.ac.uk

${ }^{1}$ Cardiac Surgery and Clinical Perfusion, Imperial College London, London, UK

${ }^{2}$ Hammersmith Hospital, Imperial College London, London, UK
}

and inflammatory markers but also expressed concern about safety. Recently, RCTs have consistently reported benefits of $\mathrm{mCPB}$, including reductions in length of stay in the intensive care unit, lower blood loss and transfusion requirements, improved renal and neurological outcomes [2-5], a higher mean arterial pressure during $\mathrm{CPB}$, a lower consumption of vasoactive drugs, and a reduced inflammatory response. A meta-analysis of 33 RCTs showed $\mathrm{mCPB}$ to be associated with a lower risk of blood loss, postoperative stroke, and mortality

\section{(O) BioMed Central}

(c) 2013 Momin et al.; licensee BioMed Central Ltd. This is an Open Access article distributed under the terms of the Creative Commons Attribution License (http://creativecommons.org/licenses/by/2.0), which permits unrestricted use, distribution, and reproduction in any medium, provided the original work is properly cited. 
compared to $\mathrm{CCPB}$ [6]. The applicability of these findings was limited by the diversity of $\mathrm{mCPB}$ technologies evaluated in the RCTs, which ranged from extremely complex, micro systems to ones very similar to $\mathrm{CCPB}$ technology.

Some of the diversity is explained firstly by advances in $\mathrm{mCPB}$ technology, which have improved the safety of $\mathrm{mCPB}[4,7]$, but also the absence of an agreed definition for the technology which allows many different systems to be included under the miniaturized umbrella. It remains a major challenge to standardise an optimal system capable of eliciting the benefits of miniaturisation while retaining an adequate safety margin. In this paper, we describe our Hammersmith mCPB system initially used by a single surgeon (JA) and now progressively adopted by the rest of the unit surgeons.

\section{Methods}

Anaesthesia is maintained using a mixture of propofol and remifentanil. Blood gas analysis and activated clotting time (ACT) are checked regularly to maintain a minimum ACT of 400 seconds during CPB. Patients are cooled to $32^{\circ} \mathrm{C}$. A cardiac index of $1.8-2.4 \mathrm{~L} / \mathrm{m}^{2} / \mathrm{min}$ is used to determine each patient's target normothermic cardiac output. Myocardial protection is achieved using either cold (4:1 ratio) blood-cardioplegia or intermittent cross-clamp fibrillation.

Our mCPB system (Sorin Group Italia) is built from a set of standard components (Table 1) tailored to specific circumstances, i.e. the patients' characteristics, planned procedure, and the perfusionist and surgical teams experience (Figure 1).

We balance Foreign Surface Area (FSA) of the system with clinical applicability to maintain patient safety (Table 2). For example, we monitor and control the negative pressure in the venous line using the patientspecific venous collapse pressure as the threshold value. The venous cannula we use (Figure 1a) facilitates optimisation in this area of our system as its design increases the patient-specific venous collapse pressure.

A venous air removal device (VARD) facilitates the management of gross and microscopic air removal, which is a key safety advantage (Figure 1b) and provides 'active' microscopic air removal, rather than the 'passive' micro air removal achieved using a ous reservoir. We prefer a centrifugal pump although a standard roller pump can also be used as long as the pump is linked to the venous line pressure (Figure 1c). We carefully consider the size of FSA we expose the patients' blood to, as well as the exposure time. For example we use an oxygenator with a very high ratio of gas exchange surface area to FSA. Manufacturers quote the gas exchange surface area but it is important to know how much FSA is required to achieve that gas exchange surface area. A well design oxygenator boasting good fluid dynamics will minimise the FSA required to provide the gas exchange surface. We use a $1.2 \mathrm{~m}^{2}$ oxygenator which provides a $1.1 \mathrm{~m}^{2}$ gas exchange surface (Figure 1d). The advantages of using a smaller $1.1 \mathrm{~m}^{2}$ gas exchange surface have to be balanced against

Table 1 Components of the standard Hammersmith mCPB circuit

\begin{tabular}{|c|c|}
\hline Prime Volume & $134 \mathrm{ml}$ (with ante grade and retrograde priming) \\
\hline \multirow[t]{8}{*}{ Foreign surface area } & Oxygenator $-1.1 \mathrm{~m}^{2 *}$ \\
\hline & VARD $-0.0105 \mathrm{~m}^{2 *}$ \\
\hline & Soft Shell Bag $0.0860 \mathrm{~m}^{2}$ *or Midi Card $-0.0535 \mathrm{~m}^{2} *$ \\
\hline & Total $-1.301 \mathrm{~m}^{2}\left(1.268 \mathrm{~m}^{2}\right)$ \\
\hline & Tubing $-0.0747 \mathrm{~m}^{2}$ \\
\hline & Arterial line Filter - $0.0300 \mathrm{~m}^{2}$ (D733, Low Prime Sorin group) \\
\hline & Pre Bypass Filter (0.5 $\mu \mathrm{m}$ filter within the arterial-venous sash (Siever, [Sorin group]) \\
\hline & 3/8 Arterial and Venous lines \\
\hline Air interface & $100 \mathrm{ml}$ in Midi Card $-8.14 \times 10^{-4} \mathrm{~m}^{2} *$ \\
\hline \multirow[t]{4}{*}{ Air handling } & Air free venting as standard \\
\hline & $2 \times 1 / 4$ polyvinylchloride lines to act as an aortic root and Left Ventricular \\
\hline & No air in soft shell bag \\
\hline & Continuous communication with surgeon \\
\hline \multirow[t]{3}{*}{ Safety features } & VARD * \\
\hline & Ramp Down function \\
\hline & Electronic clamp \\
\hline Cell saving device & Dideco Electra [Sorin group, Italy] \\
\hline
\end{tabular}

* See Figure 1 for details; VARD Venous Air Removal Device. 


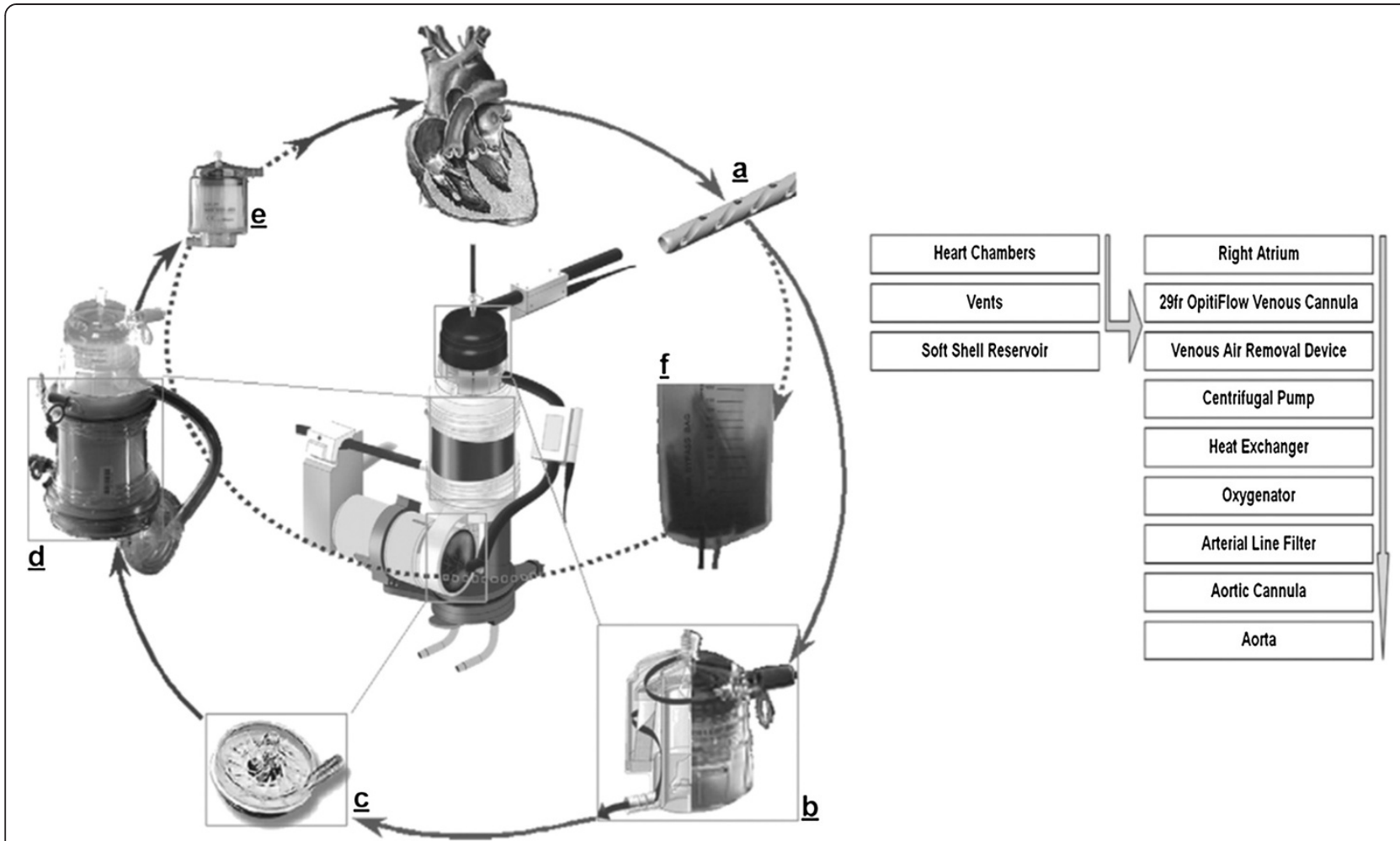

Figure 1 Schematic and flowchart of the Hammersmith mCPB system. (a) 29-French OptiFlow venous cannula (Sorin Group, Mirandola, Italy); (b) venous air removal device; (c) centrifugal pump (Revolution Cardiopulmonary Bypass; Stöckert, Munchen, Germany); (d) heat exchange, and oxygenator module (Eos [Sorin Group, Mirandola, Italy]); (e) arterial line filter; and (f) parallel soft-shell reservoir.

reducing your 'factor of safety'. This is the residual capacity of the oxygenator that is not used. In our experience, the margin remains acceptable even at normothermic levels where we would comfortably run FiO2's at $75 \%(25 \% \mathrm{FoS})$ rather than at $65 \%(35 \% \mathrm{FoS})$. Versatility is enhanced by allowing for an optional isolated softshell reservoir (SSR) or Midi card running in parallel to the systemic circulation (Figure 1f and Table 3). This option facilitates management of circulating volume in high-risk circumstances, although at the expense of increased FSA.

$\mathrm{MCPB}$ requires the patient to be used as a reservoir. Consequently, it can pose challenges, such as the need to reposition the operating table to facilitate venous drainage and filling. The use of a SSR eliminates this problem. A key feature of the SSR is its position in parallel, not in series as in CCPB, thus eliminating blood FSA exposure on every pass through the system (limiting exposure time). It has no air interface and the perfusionist manually removes any air introduced by the vent into the SSR. Therefore, a SSR can be routinely used in circumstances that are unlikely to give rise to complex air/vent management issues. For more complex circumstances, a hard shell reservoir (HSR), Midi Card, is used; despite a limited air interface, the Midi Card allows easier air management from the vent and suction because it is automated. Both of these aspects of our system can be perceived to be a disadvantage but when considered in context the advantages in terms of clinical applicability outweigh any disadvantages. Take for example the introduction of a soft-shell reservoir, clinical applicability is significantly increased, it also presents an additional FSA of $0.086 \mathrm{~m}^{2}$ which is insignificant compared to the FSA of an Oxygenator.

\section{Results}

Review of our experience using $\mathrm{mCPB}$ was approved by the clinical audit committee of the Imperial College National Health Service Trust to meet ethical and legal requirements, and individual consent was waived. From January 2010 to March 2011, a single surgeon (JA) carried out 61 isolated aortic valve replacements, 78 CABGs, 25 aortic valve replacement and CABG and 17 other operations (major aortic surgery, re-do operations or double/triple valve replacements) on 184 consecutive patients. The mean logistic Euro score was $8.4+/-9.9$ SD. The consultant performed $74 \%$ of operations and surgical residents performed the remainder under supervision. 


\begin{tabular}{|c|c|c|c|}
\hline & & $\mathrm{mCPB}$ & CCPB \\
\hline \multirow[t]{5}{*}{ Venous cannula } & & 29 Fr OptiFlow (Sorin) & 34/46 Fr 2-stage (Medtronic) \\
\hline & \multirow[t]{2}{*}{ Advantage } & $\begin{array}{l}\text { - Multi-stage and longer length (increasing drainage } \\
\text { and structural support in IVC) }\end{array}$ & - Convenient and easy placement \\
\hline & & $\begin{array}{l}\text { - Less prone to collapse and blockage due to side } \\
\text { holes and grooves }\end{array}$ & - This type of cannulae is used in common practice \\
\hline & \multirow[t]{2}{*}{ Disadvantage } & \multirow{2}{*}{$\begin{array}{l}\text { - Rigid (requiring careful placement) as it extends } \\
\text { further down the IVC }\end{array}$} & - Larger - increased risk of interaction with IVC/RA wall \\
\hline & & & $\begin{array}{l}\cdot 2 \text { stage cannula less support in IVC thus more prone to collapse and decreased drainage from Hepatic } \\
\text { veins and circulation }\end{array}$ \\
\hline \multirow{6}{*}{$\begin{array}{l}\text { Venous line and } \\
\text { drainage }\end{array}$} & & $3 / 8$ inch tubing & $1 / 2$ inch tubing \\
\hline & \multirow[t]{3}{*}{ Advantage } & - Smaller, active kinetic drainage & - Gravity syphon based \\
\hline & & - Monitored controlled drainage & - Simple, standard and convenient \\
\hline & & - Tailored to patient specific venous collapse pressure & \\
\hline & \multirow[t]{2}{*}{ Disadvantage } & & - Uncontrollable \\
\hline & & & - Not routinely monitored \\
\hline \multirow[t]{9}{*}{ VARD } & & Advisable to use in mCPB but not compulsory & $\begin{array}{l}\text { VARD is not required due to the presence of the Venous reservoir but it has been proven to be of benefit } \\
\text { in all CPB circuits [8]. However, it is not commonly used. }\end{array}$ \\
\hline & \multirow[t]{5}{*}{ Advantage } & - Enhances safety & - Cheaper \\
\hline & & - Efficient gross air removal & - Simple open system \\
\hline & & - Active micro air removal & - The reservoir filters and removes gross air easily \\
\hline & & $\begin{array}{l}\text { - Decreases FSA versus standard filters used in CPB } \\
\text { venous reservoir's }\end{array}$ & - Continuity \\
\hline & & - All air introduction into system & \\
\hline & \multirow[t]{3}{*}{ Disadvantage } & - Require perfusion experience & - No active removal of micro-embolic air (just passive) \\
\hline & & - Extra Component of circuit & - Venous reservoir in series (continued FSA exposure) \\
\hline & & $\begin{array}{l}\text { - Vented blood has to be manually returned back } \\
\text { into the systemic system }\end{array}$ & - Increases FSA \\
\hline \multirow[t]{7}{*}{ Reservoir* } & & SSR or Midi card & Venous reservoir (Sorin Evo) \\
\hline & \multirow[t]{5}{*}{ Advantage } & $\begin{array}{l}\text { - Closed (no 'in series' blood-air interface- limits FSA } \\
\text { exposure) }\end{array}$ & - Open \\
\hline & & - Decreased damage to blood cells & - Common practice \\
\hline & & - Optimises vent management & - Venting possible \\
\hline & & - Midi card 'in parallel' automatic air removal & - Low Pressure Suction and blood venting possible \\
\hline & & . & - Vented blood is automatically returned to the systemic circulation \\
\hline & Disadvantage & - SSR requires manual air bubble removal & • 'In series' Blood-air interface \\
\hline
\end{tabular}


Table 2 Advantages and disadvantages of mCPB and cCPB (Continued)

\begin{tabular}{|c|c|c|c|}
\hline & & $\begin{array}{l}\text { - No Low Pressure Suction (an issue in cases where } \\
\text { there are high volumes of LPS) }\end{array}$ & - Damage to blood cells \\
\hline & & $\begin{array}{l}\text { - Vented blood has to be manually returned back } \\
\text { into the systemic circulation }\end{array}$ & - Disguises poor suction/vent management \\
\hline \multirow[t]{6}{*}{ Centrifugal pump } & & Revolution (Stöckert, Germany) & Standard roller pump \\
\hline & Advantage & - Non-occlusive & $\cdot 1 / 2$ inch silicon tubing \\
\hline & & - Pressure regulates & - Cost-effective \\
\hline & & - Gross safety mechanism & \\
\hline & & - Less blood cell trauma & \\
\hline & Disadvantage & - Cost and training & - Occlusive (No pressure regulation) \\
\hline \multirow{6}{*}{$\begin{array}{l}\text { Heat exchanger and } \\
\text { oxygenator }\end{array}$} & & Eos (Sorin Group, Italy) & Avant (Sorin Group, Italy) \\
\hline & Advantage & - $1.1 \mathrm{~m}^{2}$ (decreased) FSA & - High 'factor of safety' \\
\hline & & - Efficient use of fibre bundle capacity & • $7.5 \mathrm{~L} / \mathrm{min}$ blood flow \\
\hline & & - high ratio of gas exchange surface area to FSA & \\
\hline & Disadvantage & - Reduced (but acceptable) 'factor of safety' & $\cdot 1.8 \mathrm{~m}^{2} \mathrm{FSA}$ \\
\hline & & & - Excessive 'factor of safety' for our patient population \\
\hline Arterial line filter & & Pall AL6 low prime & Pall AL6 low prime \\
\hline
\end{tabular}


Table 3 mCPB: soft shell reservoir and Midi card options

\begin{tabular}{|c|c|c|c|}
\hline & & \multicolumn{2}{|c|}{ Options } \\
\hline & & Soft shell reservoir & Midi card \\
\hline Patient & & All & All \\
\hline \multirow[t]{2}{*}{ Operation } & & $A \bigvee R, C A B G, A V R+C A B G$ & Complex operation, redo, Aortic root, Mitral, \\
\hline & & Experienced perfusionist * & Case selection \\
\hline \multirow[t]{2}{*}{ Device } & Parallel & Yes & Yes \\
\hline & Blood-air interface & No & Yes (minimal) \\
\hline \multirow[t]{4}{*}{ Vented Blood } & Air removal & Manual (active) & Automatic \\
\hline & & & Open reservoir \\
\hline & & & Independent of perfusionist \\
\hline & Venting & Experienced management and good communication & Easily managed, not labour intensive \\
\hline
\end{tabular}

AVR Aortic Valve Replacement, CABG Coronary Artery Bypass Graft, FSA Foreign Surface Area, IVC Inferior Vena Cava, SSR Soft shell Reservoir, VARD Venous Air Removal Device. * We begin training junior perfusionists with Midi card and after experience is gained, we move to SSR for routine cases. With further experience both by surgical and perfusionist teams, we move forward to Soft Shell Reservoir (SSR) for all cases regardless of complexity. The characteristics of these two options are described below.

Our clinical experience has led us to the following conclusion:

Venous drainage is optimally maintained using kinetic energy which provides controlled removal of fluid volume from the heart (controlled negative pressure), a benefit that is rarely discussed. We run a pressure isolator from the venous line that is connected to an electrical pressure monitor on the heart lung machine. This monitoring provides us with a digital readout of the pressure in the venous line. Accurately monitoring and controlling this quality indicator facilitates optimisation of the haemodynamic balance between circulating volume, cardiac output (arterial pump flow) and SVR.

i. Venous collapse pressure is patient-specific. It depends on the patient's anatomy and cannula size, but most importantly on the negative pressure generated by venous drainage. In a pilot study of 20 patients we found the patient-specific venous collapse pressure varies from $-8 \mathrm{mmHg}$ to -54 $\mathrm{mmHg}$. The same study showed that gravity venous drainage generates a range of $-26 \mathrm{mmHg}$ to -48 $\mathrm{mmHg}$ and vacuum assisted generates a range of -56 $\mathrm{mmHg}$ to $-79 \mathrm{mmHg}$. This collapse pressure varies from $-8 \mathrm{mmHg}$ to $-54 \mathrm{mmHg}$. Gravity venous drainage generates a range of $-26 \mathrm{mmHg}$ to -48 $\mathrm{mmHg}$ and vacuum assisted venous drainage generates a range of $-56 \mathrm{mmHg}$ to $-79 \mathrm{mmHg}$. Given that CPB most commonly utilises gravity venous drainage (uncontrolled and unmonitored), the negative pressures generated will exceed the patient specific collapse pressure for a large group of patients in our pilot. This pressure magnitude can cause venous collapse and even though it may not stop blood drainage to the circuit, the risk of venous congestion (especially Liver) and resulting sub- optimal end organ perfusion is increased. Vacuum assisted venous drainage increases this risk further. The benefits of accurately monitored and controlled kinetic venous drainage provided by $\mathrm{mCPB}$ will minimise this risk.

ii. The patient-prime interaction is optimised with ante grade and retrograde autologous priming. This method mixes the blood and prime away from the tissues and results in a reduced oncotic destabilization. As a result $\mathrm{mCPB}$ stabilises haematocrit much quicker, whereas the initial prime load for $\mathrm{C} C \mathrm{~PB}$ requires several passes through the circuit to stabilise the haematocrit (Figures 2 and 3).

Ti et al. [9] reported cardiac index targets were difficult to achieve using $\mathrm{mCPB}$. This can happen if the management of the technology is not considered, resulting in volume restrictive strategy focusing on maintaining haematocrit only. Our philosophy is to shift attention to the human management aspect of the technology, optimising patient-volume interaction, haematocrit, arterial flow and circulating volume without being volume restrictive. The $\mathrm{mCPB}$ closed system allows better informed haemodynamic balance management. Figure 2A shows the benefit in haematocrit management of gradual and pre-emptive volume addition, with the volume determined by the patient's requirement. A low haematocrit does not entail a failure of the technology if the hemodynamic balance is managed accurately and the patient requires volume, all the other advantages outlined still remain. Nevertheless, there is no doubt that $\mathrm{mCPB}$ places greater demands on the perfusionist, as it requires active, informed management throughout the operation in order to integrate optimally drug/fluid addition, blood suction, vent and SVR management. 


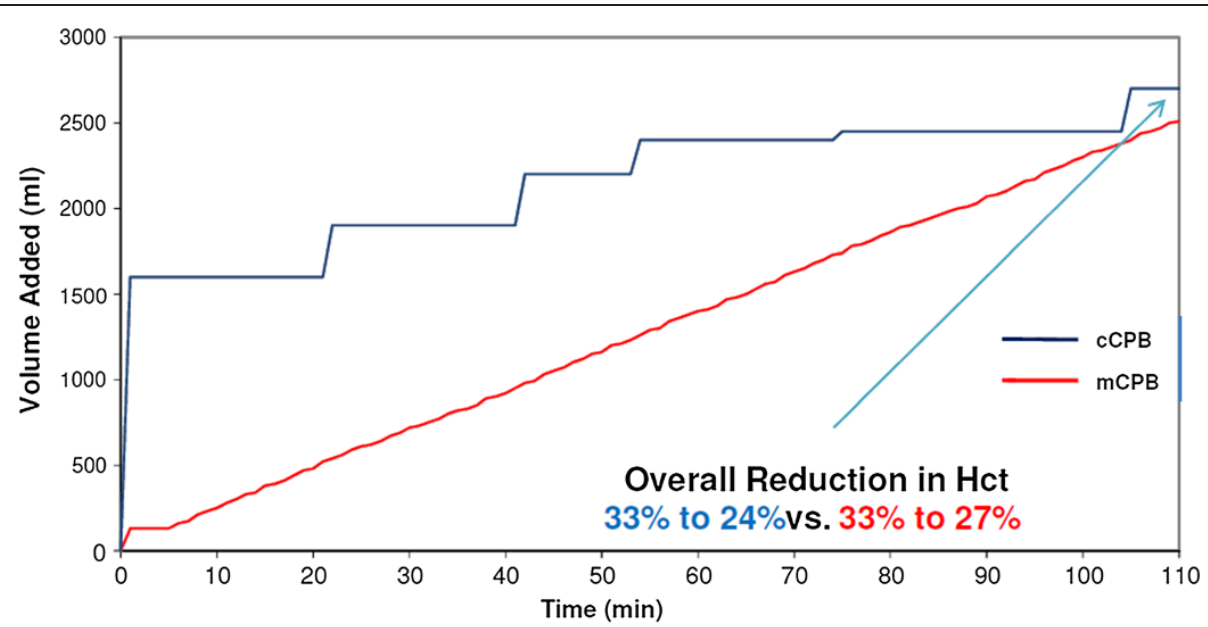

Figure 2 Haematocrit stabilisation mCPB vs. cCPB. Graphs are illustrative only; each panel is based on data for a randomly selected individual per technique: Volume Management.

The patient cohort described was completely unselected, with no exclusions due to the technical complexity of the operation. Table 4 describes the patient's preoperative, operative and postoperative characteristics. Less than $9 \%$ of patients had red blood cells transfused, and less than $5 \%$ of patients required platelets or fresh frozen plasma. The frequencies of post-operative complications were unremarkable given the nature of the cohort. No technical problems related to the use of the $\mathrm{mCPB}$ were reported throughout the all series.

\section{Discussion}

Miniaturised CPB should be viewed as a delicate balance between benefit (for the patient and publicly funded health services), intra-operative safety margins and clinical applicability rather than as a strategy to minimize the circuit without clear objectives. A common sense and informed approach needs to be applied when considering what to minimise; For example, switching from a $1.8 \mathrm{~m}^{2}$ to a $1.1 \mathrm{~m}^{2}$ oxygenator (where the latter is more efficient in terms of gas exchange) when compared to a more common strategy used by perfusion teams to limit FSA, it equates to $42 \mathrm{~m}$ of $3 / 8$ " tubing. Our choice of oxygenator facilitates a substantial reduction in FSA with an acceptable safety margin and 4.5 litre flow per minute as compared to a traditional Avant Sorin oxygenator which has $1.8 \mathrm{~m}^{2}$ FSA with an inefficient use of fibre bundles despite a relatively higher safety margin.

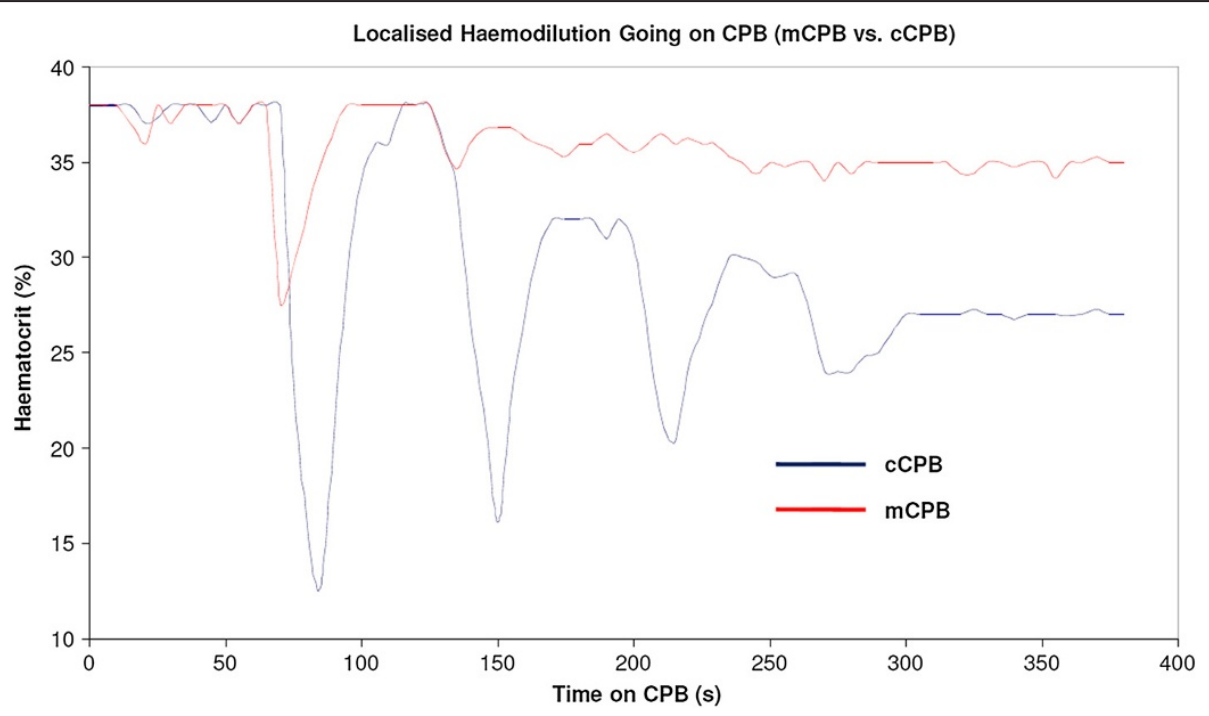

Figure 3 Haematocrit stabilisation mCPB vs. cCPB. Graphs are illustrative only; each panel is based on data for a randomly selected individual per technique: Patient/Prime Interaction. 
Table 4 Pre, intra and post-operative characteristics $(n=184)$

\begin{tabular}{|c|c|c|c|}
\hline \multirow[t]{2}{*}{ Patient data } & & \multicolumn{2}{|c|}{ Mini CPB $(n .=180)$} \\
\hline & & $\mathbf{n}$ & $\%$ \\
\hline Male & & 130 & 70.7 \\
\hline Euro score (logistic) & & & $8.4( \pm 9.9)$ \\
\hline Previous myocardial infarction & & 44 & 23.9 \\
\hline Diabetes & & 58 & 31.5 \\
\hline Hypertension & & 155 & 84.2 \\
\hline \multirow[t]{3}{*}{ Preoperative renal disease } & Creatinine $>200 \mathrm{umol} / \mathrm{l}$ & 13 & 7.1 \\
\hline & Creatinine $>200 \mathrm{umol} / \mathrm{l}$ and dialysis & 2 & 1.1 \\
\hline & Dialysis for CRF $>6$ weeks prior to surgery & 3 & 1.6 \\
\hline \multirow[t]{3}{*}{ Extent of coronary disease } & One vessel & 15 & 8.2 \\
\hline & Two vessels & 20 & 10.9 \\
\hline & Three vessels & 63 & 34.2 \\
\hline \multirow[t]{2}{*}{ Ejection fraction category } & Fair (LVEF 30-49\%) & 24 & 13.0 \\
\hline & Poor (LVEF <30\%) & 17 & 9.2 \\
\hline Cross-clamp time, (minutes) & & & $42.9( \pm 29.5)$ \\
\hline CPB time, minutes & & & $71.0( \pm 41.9)$ \\
\hline Intra-aortic balloon pump & & 4 & 2.2 \\
\hline \multirow[t]{2}{*}{ Blood product usage } & PRC & 8 & 4.3 \\
\hline & PRC, FFP, platelets & 5 & 2.7 \\
\hline Total chest tube drainage $(\mathrm{ml})$ & & & $801( \pm 483)$ \\
\hline Reoperation for bleeding & & 2 & 1.1 \\
\hline Renal Complications & & 3 & 1.6 \\
\hline Stroke & & 1 & 0.5 \\
\hline In hospital death (30 days) & & 2 & 1.1 \\
\hline
\end{tabular}

CRF Chronic Renal Failure, LVEF Left Ventricular Ejection Fraction, CPB Cardiopulmonary Bypass, FFP Fresh Frozen Plasma. Mean and standard deviation.

$\mathrm{mCPB}$ requires active participation, awareness and increased technical knowledge of the cardiac team. With such involvement, $\mathrm{mCPB}$ enhances monitoring and consequently reduces introduction of air from sample lines, ports, the surgical field and additions of fluid. It also brings to the attention of the perfusionist poor vent and suction management, encourages good multidisciplinary communication, and promotes continuous monitoring of SVR and hemodynamic balance. Highlighting suboptimal CPB management improves quality. Emphasising the introduction of air from sample ports and fluid additions lead to a decrease in air emboli and may reduce the risk of a neurological complication. Venting is important to provide a bloodless field with optimal vision; it should be balanced with the resultant damage caused to the blood constituents. $\mathrm{mCPB}$ promotes optimisation of this balance. All pericardial suction blood is processed via cell saving technology.

Before undertaking more complex cases with $\mathrm{mCPB}$, perfusionists should acquire the skill set to manage
$\mathrm{mCPB}$ in low risk circumstances because it takes time to learn to manage $\mathrm{mCPB}$ technology to maximise its benefits. However, we believe the greatest benefits of $\mathrm{mCPB}$ may arise for more complex operations and higher risk patient populations with significant co-morbidity. Despite evidence that $\mathrm{mCPB}$ has important clinical benefits [6] it has not been widely implemented, probably because previous RCTs evaluated diverse systems several of which had limited clinical applicability to usual care.

After initial development of our $\mathrm{mCPB}$ technique and implementation in usual care by one surgeon, it is now progressively adopted by the rest of the departmental surgeons.

\section{Conclusion}

The Hammersmith mCPB is a "next generation" system which uses standard commercially available components. It aims to maintain safety margin and the benefit of miniaturised system whilst reducing the human factor demands. 


\section{Competing interest}

The authors declare that they have no competing interests.

\section{Authors' contributions}

AM designed the study and drafted the manuscript; MS analysed the data, contributed to the study design and drafting the manuscript; JM was the main contributor to developing the mCPB; GY helped designing the system as a perfusionist; BR contributed to drafting the manuscript; JA was the main user of the system as a surgeon; GA contributed to drafting the paper. All authors read and approved the final manuscript.

\section{Acknowledgement}

This work was supported by the British Heart Foundation, the NIHR Imperial College Trust Biomedical Research Center and the NIHR Bristol

Cardiovascular Biomedical Research Unit. All the contributors met the criteria for authorship and included as the co-authors.

Received: 5 March 2013 Accepted: 27 May 2013

Published: 3 June 2013

\section{References}

1. Nollert G, Schwabenland I, Maktav D, Kur F, Christ F, Fraunberger P, Reichart B, Vicol C: Miniaturized cardiopulmonary bypass in coronary artery bypass surgery: marginal impact on inflammation and coagulation but loss of safety margins. Ann Thorac Surg 2005, 80(6):2326-2332.

2. Castiglioni A, Verzini A, Pappalardo F, Colangelo N, Torracca L, Zangrillo A, Alfieri O: Minimally invasive closed circuit versus standard extracorporeal circulation for aortic valve replacement. Ann Thorac Surg 2007, 83(2):586-591.

3. Abdel Aal M, ElNahal N, Bakir BM, Fouda M: Mini-cardiopulmonary bypass impact on blood conservation strategy in coronary artery bypass grafting. Interact Cardiovasc Thorac Surg 2011, 12(4):600-604.

4. Anastasiadis $K$, Argiriadou $H$, Kosmidis MH, Megari $K$, Antonitsis $P$, Thomaidou E, Aretouli E, Papakonstantinou C: Neurocognitive outcome after coronary artery bypass surgery using minimal versus conventional extracorporeal circulation: a randomised controlled pilot study. Heart 2011, 97(13):1082-1088.

5. Remadi JP, Rakotoarivello Z, Marticho P, Trojette F, Benamar A, Poulain H, Tribouilloy C: Aortic valve replacement with the minimal extracorporeal circulation (Jostra MECC System) versus standard cardiopulmonary bypass: a randomized prospective trial. J Thorac Cardiovasc Surg 2004, 128(3):436-441.

6. Biancari F, Rimpilainen R: Meta-analysis of randomised trials comparing the effectiveness of miniaturised versus conventional cardiopulmonary bypass in adult cardiac surgery. Heart 2009, 95(12):964-969.

7. El-Essawi A, Hajek T, Skorpil J, Boning A, Sabol F, Hausmann H, Ostrovsky Y, Harringer W: A prospective randomised multicentre clinical comparison of a minimised perfusion circuit versus conventional cardiopulmonary bypass. Eur J Cardiothorac Surg 2010, 38(1):91-97.

8. Willcox TW, Mitchell SJ, Gorman DF: Venous air in the bypass circuit: a source of arterial line emboli exacerbated by vacuum-assisted drainage. Ann Thorac Surg 1999, 68(4):1285-1289.

9. Ti LK, Goh BL, Wong PS, Ong P, Goh SG, Lee CN: Comparison of minicardiopulmonary bypass system with air-purge device to conventional bypass system. Ann Thorac Surg 2008, 85(3):994-1000.

\section{Submit your next manuscript to BioMed Central and take full advantage of:}

- Convenient online submission

- Thorough peer review

- No space constraints or color figure charges

- Immediate publication on acceptance

- Inclusion in PubMed, CAS, Scopus and Google Scholar

- Research which is freely available for redistribution 